\title{
X-Ray Mapping and Analysis of the Interfacial Region of Kiln Cast Composites
}

\author{
T.J. Lucey ${ }^{*}$, P.G. Huggett ${ }^{* *}$, R. Wuhrer ${ }^{* * *}$ K. Moran ${ }^{* * * *}$ and W.Y. Yeung ${ }^{*}$ \\ * Department of Physics and Advanced Materials, University of Technology, Sydney, Australia \\ ** Materials Solutions Pty Ltd, Thornlie, Western Australia, Australia \\ *** Microstructural Analysis Unit, University of Technology, Sydney, Australia \\ ${ }^{* * * *}$ Moran Scientific Pty Ltd, P.O. Box 651Goulburn NSW 2580 Australia
}

\section{Introduction}

Over the past decade, a number of new processes for the joining of dissimilar materials have been developed [1-3]. These techniques, while first being used within the wear industry to join wear resistant white iron to various substrates, could be used in the future for the joining of a wide variety of dissimilar metals.

These new techniques permit the creation of complex shaped composites, overcoming one of the major limiting factors when creating wear composites using existing techniques. Traditionally these composites have been created in a vacuum furnace in order to reduce oxidation at the interface but recently there have been a number of advances in the production of kiln cast composites with manufacturers desiring to create these composites in standard air atmospheres. Through the use of x-ray mapping (XRM), and electron back scattered diffraction (EBSD) analysis, a better understanding of the interface of this new generation of composites can be gained. Results from this investigation on a number of dissimilar bonded materials using varying processing conditions are presented.

\section{Results and Discussion}

Fig. 1(a) shows a schematic diagram detailing the procedure used in the manufacture of both wear resistant white iron/310 stainless steel and white iron/mild steel cast joints. All samples were cross-sectioned and polished to a $0.25 \mu \mathrm{m}$ finish using diamond abrasives followed by chemical-mechanical polishing using colloidal silica in order to remove final mechanical damage. A Zeiss Supra 55VP FEGSEM and JEOL35CF SEM with a Moran Scientific Microanalysis X-ray mapping system was used for quantitative investigation of the samples.

The first set of composites created consisted of white iron cast onto a 310 stainless steel substrate. Stainless steel 310 was chosen as the substrate material due to it's high temperature oxidation resistance which is ideal when creating these kiln cast composites in a standard air atmosphere. It can be seen in Fig. 1(c) that the carbides have diffused from right to left out of the white cast iron into the previously carbide free 310 stainless steel. This image shows a stringer like growth mechanism of the carbides with the stringer joining another and then growing as a single carbide. It was observed that eutectic carbides were forming at this triple point.

Fig. 2 shows a pseudo-coloured X-Ray map of the 310 stainless steel/white iron interfacial region. This sample was created with small additions of both manganese (in order to aid wetting of the steel substrate) and graphite (which is added in order to scavenge residual oxygen around the interface as the sample is heating up). Investigations of the interface revealed no cracking and excellent bonding between the two metals. Fig. 3 shows the difference between the interface of 310 stainless steel/white iron and mild steel/white iron composites. It can be seen that the carbides diffuse freely across the interface of the 310 stainless steel/white iron while a carbide free region resides at the interface of the mild steel/white iron. 
Research work on quantitative x-ray mapping, EBSD analysis results, interpretation of scatter diagrams and the clusters observed will be discussed as well as the observed microstructure as a function of process conditions.

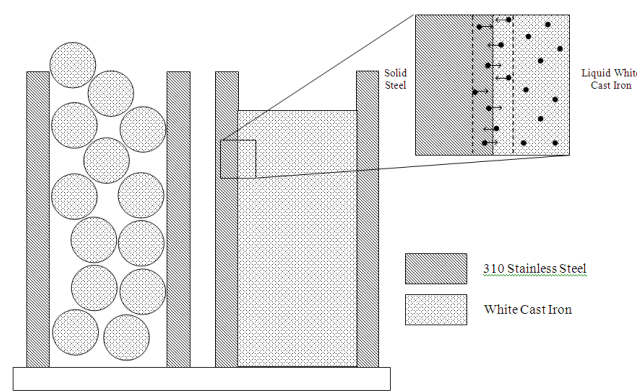

(a)

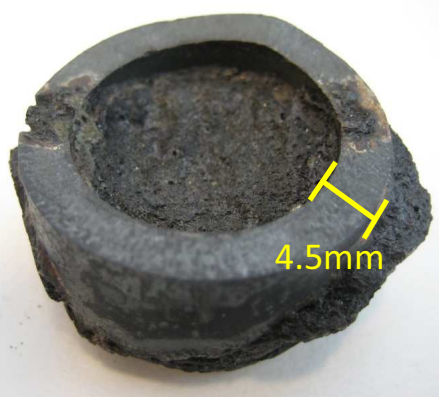

(b)

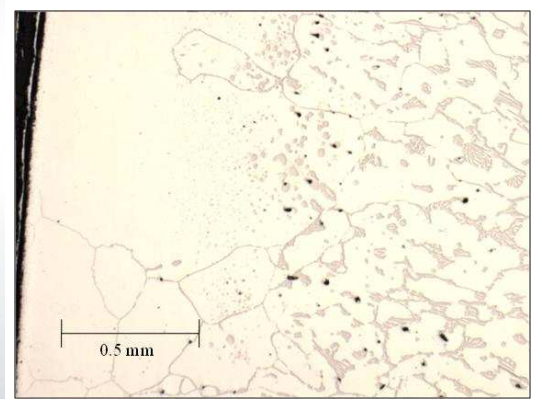

(c)

Fig. 1. (a) Schematic of cylindrical test samples. (b) Cast sample (c) Optical micrograph of interfacial region.

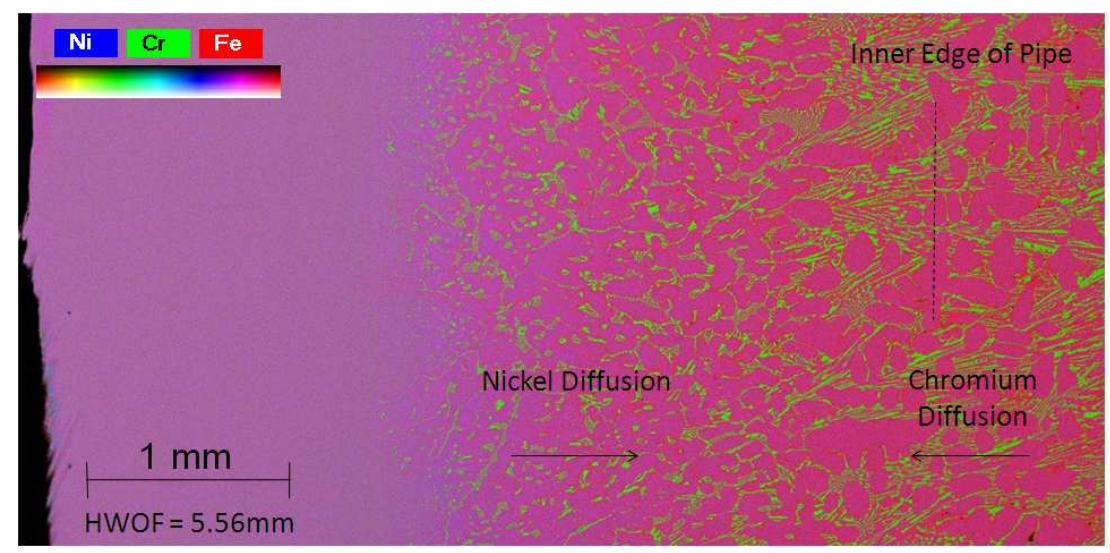

Fig. 2. X-Ray map of interface between 310 stainless steel and white iron. X-ray maps were collected at $20 \mathrm{kV}$ accelerating voltage using a Moran Scientific energy dispersive x-ray analysis and mapping system attached to a Jeol 35CF SEM.

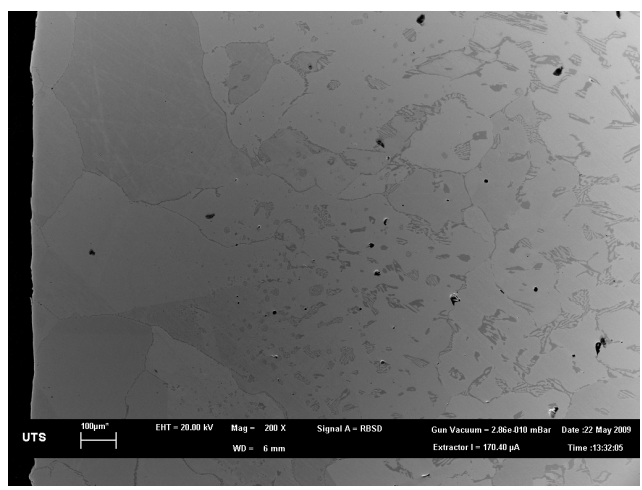

(a)

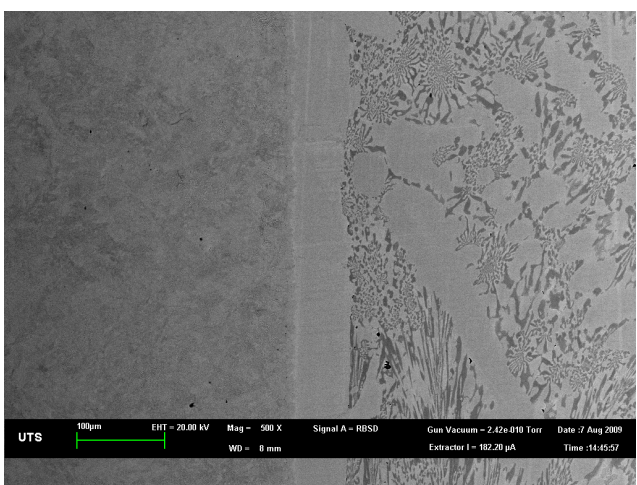

(b)

Fig. 3. (a) 310 stainless steel/white iron interface and (b) Mild steel/white iron interface.

[1] Huggett, P.G. and B. Ben-Nissan, Development Of A Low Melting Point White Cast Iron For Use In Composite Alloy Manufacture. Materials Forum, 2007. 31: p. 16-23.

[2] Huggett, P.G., et al., A novel metallurgical bonding process and microstructural analysis of ferrous alloy composites. Materials Forum, 2005. 29: p. 83-88.

[3] Huggett, P.G., et al., Composite alloy wear parts for use in the mining industry. Materials Forum, 2006. 30: p. 23-29. 